\title{
Oliveira, Laura de \\ Guerra fria e política editorial: \\ a trajetória das Edições GRD e a campanha anticomunista \\ dos Estados Unidos no Brasil (1956-1968) \\ Lucia Grinberg*
}

Maringá: Eduem, 2015. 274p.

Era comum em resenhas bibliográficas relacionadas à história política do Brasil republicano a constatação de que historiadores e cientistas sociais se dedicavam especialmente ao estudo das esquerdas, negligenciando as direitas. O panorama mudou. Nos anos 2000 houve um crescimento significativo na produção de teses e dissertações dedicadas a intelectuais, movimentos e partidos políticos de direita nos programas de pós-graduação em história no país. No campo específico dos estudos sobre o movimento integralista, as pesquisas avançaram para além dos anos 1930, buscando mostrar a presença de integralistas na vida política institucional no período da experiência democrática instaurada em 1945, a vitalidade de intelectuais e periódicos integralistas, assim como a diversidade de trajetórias individuais e de memórias de militantes. Guerra fria e política editorial é expressão da ampliação e do amadurecimento da área. Elaborado originalmente como tese de doutorado, defendida em 2013 no Programa de Pós-Graduação em História da Universidade Federal de Goiás (UFG), obteve menção honrosa no Prêmio Capes de Teses (2014) e ganhou o Prêmio Anpuh de Teses (2015).

Com base no estudo de caso sobre o editor Gumercindo Rocha Dorea e de suas Edições GRD, a historiadora Laura de Oliveira desenvolve uma reflexão relevante e atual sobre o campo das direitas políticas ao mostrar as possibilidades de alianças apesar da diversidade de inspirações doutrinárias. No caso, ela aborda como um militante integralista, admirador de Plínio Salgado, pôde contar com o financiamento do governo norte-americano para promover o anticomunismo em nome da democracia. Na primeira parte do livro, "a experiência”, Laura de Oliveira apresenta as articulações entre as Edições GRD, o

\footnotetext{
* Programa de Pós-Graduação em História, Universidade Federal do Estado do Rio de Janeiro (UniRio). Rio de Janeiro, RJ, Brasil. luciagrinberg@gmail.com
} 
movimento integralista e a United States Information Agency (USIA). Na segunda parte, "a palavra", desenvolve um estudo propriamente da "obra editorial”. Para investigar os integralistas e seus aliados no Brasil, Oliveira consultou acervos considerados estratégicos por especialistas, como o Fundo Plínio Salgado (Arquivo Público Histórico de Rio Claro) e o Fundo IPÊS (Arquivo Nacional). Nos Estados Unidos, pesquisou documentação relativa à USIA no National Archives and Records Administration (NARA), e ao Franklin Book Programs, na Mudd Manuscript Library da Princeton University.

Na primeira parte do livro, "a experiência", em narrativa bem estruturada, a historiadora analisa os contextos variados que combinados permitem compreender a trajetória política e empresarial de Gumercindo Rocha Dorea: as tradições e a estrutura das organizações integralistas, a política externa norte-americana de intercâmbio cultural e a parceria com o Instituto de Pesquisas e Estudos Sociais (IPÊS). Em 1956, quando o jovem baiano Gumercindo Rocha Dorea criou as Edições GRD, era filiado ao Partido de Representação Popular (PRP), liderado por Plínio Salgado, e participava ativamente de iniciativas integralistas no campo da cultura. Dorea foi editor do jornal integralista A Marcha (1952-1955), diretor da Livraria Clássica Brasileira (1956-1957) e presidente da Confederação Nacional dos Centros Culturais da Juventude (1952-1953 e 1957-1958). A autora dialoga com obras recentes sobre a Ação Integralista Brasileira (AIB) e o PRP, indicando ao leitor contribuições relevantes na área.

As Edições GRD também foram beneficiadas pelas iniciativas da "cultural war", a política norte-americana de intercâmbio cultural implementada nos anos da guerra fria. Desde os anos 1950 a editora obteve recursos por meio da política de financiamento de traduções do Book Development Program, desenvolvido pela USIA, entidade diplomática que vigorou entre 1953 e 1999. De acordo com as fontes pesquisadas, a USIA promoveu cerca de 1.340 traduções de originais de língua inglesa lançados no mercado editorial brasileiro. A GRD teve 48 traduções patrocinadas pela agência. Muitas editoras brasileiras receberam subsídios por meio do programa que incentivava a publicação de obras que veiculavam do elogio ao american way of life ao anticomunismo. Dorea se destacou pela seleção de obras marcadamente anticomunistas.

Na conjuntura anterior ao golpe de 1964, as Edições GRD se associaram ao IPÊS, como outros estudos já apontaram. No entanto, Laura de Oliveira mostra que a associação era um desdobramento de parceria anterior às conspirações para depor o presidente João Goulart - havia uma sintonia entre os objetivos políticos da USIA, do IPÊS e da GRD, todos desejavam combater as esquerdas e desestabilizar o governo federal. Apesar de a campanha ipesiana se caracterizar 
por penhorar o destino brasileiro às instituições liberais, Dorea participou ativamente. Em contraste com os “camisas verdes" dos anos 1930, a partir de 1945, os militantes do integralismo, então denominados “águias brancas”, construíram uma nova identidade política. Não se isolaram na doutrina original, apropriaram-se das regras da democracia representativa instaurada e continuaram operando por intermédio do PRP e de iniciativas culturais, como as Edições GRD, mesmo estando longe de compartilhar ideais liberal-democráticos.

Na segunda parte do livro, "a palavra", na perspectiva de Raymond Williams, Laura de Oliveira investiga as conexões entre experiência social e literatura, combinando história política, história do mercado editorial e estudos literários. De acordo com a autora, ao analisar o conjunto da obra das Edições GRD, de 1956 a 1968, é possível identificar um sentido comum: a divulgação do comunismo como distopia contemporânea, como tragédia iminente que ameaçava o Brasil e a América Latina. As Edições GRD tiveram duas coleções importantes, a "Coleção Política Contemporânea", traduções financiadas pela USIA principalmente, e "Clássicos Modernos da Ficção Científica" (posteriormente intitulada “Ficção Científica GRD”). O anticomunismo estava presente em ambas.

De 1958 a 1971, as Edições GRD publicaram cerca de trinta livros do gênero ficção científica, traduções e originais de autores brasileiros, sendo considerada responsável pela consolidação do gênero no país nos anos 1960. Em diálogo com estudos sobre ficção científica, Oliveira mostra como o gênero lida com alegorias utópicas e seu par coexistente, a distopia, ao narrar mundos alternativos, outros planetas, territórios longínquos ou paraísos perdidos. Durante a guerra fria, nos clássicos da literatura de ficção científica de língua inglesa, Aldous Huxley, George Orwell e Ray Bradbury contrapõem sociedades baseadas nos ideais de liberdade e individualidade a Estados totalitários. Nas publicações de ficção científica da GRD, Oliveira identifica "uma permanente associação entre a consagração dos projetos totalitários (marcadamente, do comunismo soviético) em ambiente internacional, o esforço da União Soviética de colonização dos países democráticos, sua ação na América, confirmada pela então recente revolução em Cuba, e seu conjecturado avanço sobre o Brasil” (p.195).

No mesmo sentido, durante o governo João Goulart, a "Coleção Política Contemporânea" editou títulos como Anatomia do comunismo (1963) e Cuba, nação independente ou satélite (1963). Oliveira apresenta os enredos, os paratextos e reproduções de capas das publicações, introduzindo o leitor em um universo trágico comum às obras de ficção científica e de política contemporânea. Na orelha de Anatomia do comunismo (1963), Dorea inscreveu a sua mensagem: pretendia levar "aos homens públicos responsáveis pela manutenção 
do sistema democrático na vida política brasileira, a lição que nos vem dos que têm sofrido, na própria pele, a ameaça diuturna das hostes bélicas que, a qualquer momento, poderão descer do leste europeu" (grifos do autor, p.202).

$\mathrm{Na}$ historiografia relativa a partidos políticos no Brasil republicano, desde os anos 1990, há teses que desafiam as interpretações tradicionais que enfatizam a distância entre as organizações partidárias e a sociedade, assim como as que destacam as descontinuidades das legendas, desconsiderando as intervenções sucessivas de ditaduras no sistema partidário. No presente caso, as intervenções extinguindo os partidos políticos por decreto atingiram a AIB, no Estado Novo, e, posteriormente, o PRP, em 1965, com o Ato Institucional no 2. Guerra Fria e política editorial é uma bela contribuição para o debate. Partindo do caso de Gumercindo Rocha Dorea, baiano de Ilhéus, a autora mostra a possibilidade de, diminuindo a escala de análise, investigar trajetórias individuais tendo em vista o estudo de atores coletivos, como partidos políticos. Ao se dedicar ao estudo das Edições GRD, Oliveira investiga as relações entre atividade editorial e militância político-partidária, considerando as especificidades dos dois campos: as características de negócio e a necessidade de financiamento, a marca da afinidade ideológica e a existência de uma rede de sociabilidade de intelectuais, antigos membros da AIB, filiados e simpatizantes do PRP, reunidos em torno da editora. Afinal, apresenta os integralistas, entusiastas de um movimento de extrema direita, inseridos na sociedade, e mostra que os militantes se articularam em novas organizações, não permaneceram isolados.

O interessante em Guerra Fria e política editorial é justamente a percepção das dinâmicas, continuidades e descontinuidades do movimento integralista, e da possibilidade de articulação com o próprio governo norte-americano, antes combatido pelo nacionalismo exacerbado, o anticosmopolitismo e o antiliberalismo, próprios do integralismo. Em 1967, as iniciativas da USIA foram denunciadas nos Estados Unidos como tentativa de manipular a opinião pública por intermédio de editoras da iniciativa privada. Em pouco tempo, com o fim do convênio, as Edições GRD voltaram a reeditar autores integralistas e Dorea passou a comandar igualmente a "Voz do Oeste", editora fundada por Plínio Salgado. Guerra Fria e política editorial mostra, portanto, a parceria entre liberais norte-americanos e integralistas brasileiros, assim como o enraizamento das tradições integralistas e a capacidade organizacional de seus quadros.

Resenha recebida em 26 de janeiro de 2016. Aprovada em 13 de fevereiro de 2016. 